\title{
Extent of Compliance of a Higher Education Institution for a University System
}

\author{
Roger S. Ambida ${ }^{1}$, Rizalina A. Cruz ${ }^{2}$ \\ ${ }^{1}$ Department of English and Literature, Lyceum of the Philippines University, Manila, Philippines \\ ${ }^{2}$ College of Arts and Sciences, Lyceum of the Philippines University, Manila, Philippines
}

Email address:

roger_ambida@yahoo.com.ph (R. S. Ambida), hopesaag@yahoo.com (R. A. Cruz)

\section{To cite this article:}

Roger S. Ambida, Rizalina A. Cruz. Extent of Compliance of a Higher Education Institution for a University System. Science Journal of Education. Vol. 5, No. 3, 2017, pp. 90-99. doi: 10.11648/j.sjedu.20170503.13

Received: January 15, 2017; Accepted: March 31, 2017; Published: April 12, 2017

\begin{abstract}
Higher Education Institutions in the Philippines are being confronted by transformations caused by a process of interaction and integration among different nations driven by international commerce. With the modified global learning, colleges and universities have to capacitate themselves to offer quality degree programs which will be attuned to world class standards. The Commission on Higher Education in the Philippines has supported the development of higher education institutions by engaging them in the process of promoting a culture of international quality. The study conducted determines the compliance of the subject universities on certain standards of a university system as aligned to becoming a globalized structure. The study is anchored on the framework of Provus' Discrepancy Model for Curriculum Evaluation Method. Based on this pattern, particular discrepancies can be determined and resolved between a pre-determined set of standards and what actually the current status of a particular area being studied. A survey was conducted to ascertain the extent of compliance of some university campuses to the standards of a University System. The respondents of this study are composed of university presidents, vice presidents for academic affairs, planning officers, deans, directors, heads, coordinators, faculty representatives and student Leaders from universities and colleges that belong to university systems. The continuing development plan crafted by the researcher could be a significant basis for other institutions to transform towards a globalized system.
\end{abstract}

Keywords: Higher Education, Higher Education Institutions, University System, Curriculum Evaluation, Provus Discrepancy Model, Commission on Higher Education

\section{Introduction}

\subsection{The Problem and Its Background}

The current treatise on global education has been modified from education to lifelong learning and from the transfer of professional knowledge to development of learner competencies.

Employment is no longer fixated in local settings. These days, the possibility of being repositioned to other countries is feasible since transnational corporations can just relocate jobs to their utmost benefit. Based on the Primer on the Quality Assurance and Institutional Sustainability Assessment of HEIs, there will be many factors influencing relocation, including cost, access to markets, and the regulatory environment of a country among others.

In a world where borders have already begun to collapse, the Philippine higher education institutions can only survive if they can offer quality degree programs which will be attuned to world class standards. In conjunction with this, it is also significant that these institutions will also be able to produce graduates equipped with lifelong learning competencies. Hence, improving human resources with a range of knowledge and proficiency to sustain development needs of the country is already a necessity.

Apropos of these underlying conditions, the Commission on Higher Education (CHED) supports the development of HEIs into mature institutions by engaging them in the process of promoting a culture of quality. Premised on a shared understanding of quality, CHED encourages institutional flexibility of Higher Education Institutions (HEIs) in translating policies into programs and systems that lead to quality outcomes, assessed and enhanced within their respective internal quality assurance (QA) systems [1]. 
A University System according to CHED Memorandum Order No. 08 s. of 2003, is an organized academic entity composed of separate but interrelated units, at least one of which has university level status. It has a single board that is responsible for the formulation of system-wide policies and programs that govern a University System. The System shall have the general powers of a corporation set forth in the Corporation Law. A University System must have a clearly defined organization that is governed primarily by the board and by a set of officers, both system-wide and for each constituent unit [2].

The governing body or board that is commonly called as Board of Trustees/Directors/Regents has full powers of organization and governance of the System and is vested with the responsibility of formulating policies common to all units of the system. The exercise of the university's corporate power is also vested exclusively in the board.

The system administration shall coordinate and integrate system-wide functions and activities. The University System's Chief Executive Officer and head of the system administration (may be called President) is appointed directly by and is responsible to the governing board. All other officers of the University System are responsible to the Chief Executive directly through designated channels. The Chief Executive is responsible for the implementation of policies approved by the governing board and the administration of all operations of the University System. Among the Chief Executive's most important functions are consultations with the heads of the constituent universities/colleges of the System on academic policies, recommendations to the board on the academic plans of the constituent universities/colleges and presentation of a single budget for the entire University System.

A college/university may be made part of the University System only if at least fifty-percent $(50 \%)$ of its tertiary program offerings have Level II accreditation and if more than fifty-percent $(50 \%)$ of its student population is at the tertiary level. An existing University System intending to include an additional constituent unit must seek the prior approval of the Commission and prove compliance with the requirements under this Order.

Each constituent unit in the University System will have its own Chief Executive Officer (may be called Chancellor) to whom broad powers shall be delegated by the board for the organization and operation of the constituent unit. The governing board shall define the extent of autonomy of each constituent unit. The board shall also define the organization structure of each unit. The administration of a constituent unit shall be responsible for the academic, administrative, and service functions of the unit.

To understand fully higher education as an organization, the university must first be considered as an open system. An open-systems approach acknowledges that organizations are embedded in multiple environments, both technical and institutional, to which the organization must respond [3].

Societal demands regarding the role of higher education have shifted dramatically in recent years, pressuring campuses to think of themselves largely as an industry rather than as a social institution [4]. While state-level attention to academic programs was hardly new, the degree of heat and attention increased dramatically as well as the impact on faculty has been substantial since its inception.

In addition, there is an increasing pressure to "systematize" public systems of higher education, as state boards use their coordinating authority to eliminate duplicative programs and move underprepared students to lower levels of the system [5].

Every year, the dilemma of higher education institution is exponentially growing. The inevitable demand for global and national sustainability becomes apparent as impending pressures. With policies and structures from bureaucracy, many academics are tussling against societal and economic changes in order to stand their ground to values and professional practice that are traditionally dependent on pre-modern forms of governance and organization.

However, since forces of educational paradigm shifts, both cyclical and structural, have accelerated transformation of a learning environment, a university system become foreseeable.

In adopting a university system, the internal governance of higher education institutions has to undergo structural changes precipitated by information revolution and transformed learning environment.

In concert with educational policies and organization, higher education institutions transforming into a university system can boost institutional efficiency without curbing academic freedom and other organizational mandates. Viewed from this perspective, a university system can go across economic sectors redounding to the benefit of the country's roadmap towards further development.

The establishment of this structured academic entity that is both a body corporate and a politic, nevertheless, entails a process. This process includes a submission to definitive guidelines as mandated by a government commission. Since it will also articulate open interaction between shareholders and other stakeholders, it is imperative that adherence to certain standards are met.

According to Hooker, fundamentally the system civilization necessitates the appropriate institutional environment that produces a university system. In the transformation and development process of some higher education institutes, the church has been the principal guide and was mainly in control to promote the clergy and a small number of secular officials. Some higher education institutes and universities had to re-assign the control of their operation from church to the secular regime following the rise of nation-state in the process of education nationalization. Consequently, the leading force that has been affecting and constraining the development of universities is the government. This has made the university bear the influences of the government and market forces along with the fast progression of higher education. Despite its flagging academic strength and rationale, the university still upholds its core value of autonomy. The university has indeed been within the perimeter of government intervention and market penetration.

Aside from those, the expansion towards mass higher 
education without forgoing the delivery of quality instruction has become a growing concern. Another challenge is the cost-effectiveness as well as the efficiency of operating higher education institutions particularly in developing countries where there is an increase in population thereby adds to the number of school enrollment.

\subsection{Statement of the Problem}

This study aimed to determine the compliance of the subject universities to the requirements in applying for a University System as prescribed in CHED Memorandum Order No. 08 s. of 2003 in order to transform the campuses to a university system. Specifically, this paper intended to answer the following problems:

1. What are the requirements in applying for a University System pursuant to CHED Memorandum Order No. $08 \mathrm{~s}$. of 2003 ?

2. What benefits have been accorded to the recognized University Systems and to what extent?

3. What is the extent of compliance of the five (5) $L P U$ campuses to the following requirements in applying for a University System as embodied in CHED Memorandum Order No. 08 s. of 2003:

Control and Power of the Governing Board, Percentage of Accredited Constituent Units, Complementation of Program Offerings with consideration to physical and human resources as well as the needs and development priorities of the campus area. Number of Faculty and Staff and their Qualification, Source and Appropriation of University Budget, Mechanism for the Coordination and Integration of Research and Extension Services, Provision of a Cross Crediting Mechanism, Conformity of Facilities and Equipment to the Standards set by the Commission in Higher Education, and Conformity of the Site and Buildings to the existing laws, rules and regulation of the Commission

4. What are the gaps between the existing University Systems as well as the colleges of Lyceum of the Philippines University (LPU) as regards to the requirements in applying for a University System?

5. How may the findings be utilized in preparing a Continuing Development Plan to transform LPU institutions to a University System?

\subsection{Assumptions}

This study is premised on the following assumptions:

1. That the information or data obtained are reliable and valid

2. That the five (5) campuses of LPU being studied have moderately complied the requirements embedded in CHED Memo No. 08 s. of 2003 based on the following aspects:

leadership and governance, organization and administration, program offerings, faculty and staff, source and appropriation of the university budget, research and extension services, cross crediting mechanism, facilities and equipment, site and buildings, and a designated university status;
4. That, to a certain extent, the five (5) LPU campuses have fulfilled requirements in applying for a University System.

5. That there are particular moderate gaps between existing universities as well colleges of LPU and the requirements in applying for a University System; and

6. That the findings can be utilized in preparing a Continuing Development Plan to transform LPU institutions to a University System.

\subsection{Significance of Study}

Socio-academic awareness is important for educational growth. For this reason, several groups of people may benefit from the findings of this dissertation. The results of this study may be of great value to the following:

The findings of this study may serve as a guide for the Academic Administrators of LPU and other Academic Institutions in consolidating their plans and executing them in sync with other units or branches under the same system.

This study may also provide Higher Education Administrators the reference to re-think and re-organize their approach (es) in managing their educational units to work as a structured system so as to achieve the end goals.

Furthermore, this may enhance the University Students awareness of their administrative school environment that directs them to be more observant of rules and regulations thereby ascertaining their track towards the mission-vision of the university where they are enrolled.

At the same time, Higher Education Faculty Members may profit from the results of this study because they may be more conscious of their crucial role in aligning their learning objectives as well as learning plans to the main objectives of a university as part of a larger mechanism of a system.

Finally, this paper may be beneficial to Future Researchers who may undergo similar studies because certain groundwork of information regarding university transformations and system will be presented.

\subsection{Scope and Limitations}

This study is limited to the transformation of the subject universities namely: St. Paul University System, University of Perpetual Help System, University of Rizal System and Lyceum of the Philippines University to a university system. Specifically, it has revolved around the processes that the subject university systems and Lyceum of the Philippines University have undergone in its conversion into a structured organization. As a system, the administrative mechanism of the subject universities, along with its units in LPU Campuses in Manila, Makati, Batangas, Laguna, and Cavite underwent all external and internal modifications. As such, this paper also described the coordination of plans and implementation among the units with consideration to their strengths, weaknesses, opportunities, and threats.

However, there is no assumption that all university systems in the Philippines had undergone an identical transformation with the subject universities or had the same 
underlying factors that Lyceum of the Philippines University and its campuses have experienced. Furthermore, this study did not assume that the pattern of the subject universities along with LPU transformation into a university system is indicative of a general model for other universities to follow.

\section{Review of Related Literature}

\subsection{Literature}

The beginnings of higher education are still arguable. Regardless whether they started from Paris, Oxford, or Bologna, researchers settle that they started in the beginning of 13 th century. Since then, it has been stable because higher education is still basically a process of imparting knowledge and information by means of lectures and college-level presentations to learners. However, it is expected that the future state of higher education is at the threshold of change. College educators and administrators habituate themselves to planning and discussing about changes that are drawing closer. Whether a threat or an opportunity, the coming of changes may have anesthetized these institutional managers to its significance. Indeed, technology and globalization have transformed the track of life. Such shifts have repositioned them en route for diverse economic forms and academic culture. Aside from harnessing the power of digital technology and responding to the information revolution, other challenges include the cost effectiveness of higher education and the efficiency of operating higher education institution. The opportunities and challenges are far greater than at any previous time in higher education's 750-year history. By 2010, there were limited growth and attempt in the transfer of authority. Reduced public funding on often a dramatic scale helps explain a campaign for greater autonomy, particularly among the top tier public universities in various states [6].

However, the decrease in state-controlled universities could also be ascribed to the change of public opinion and attitude. This attitude was caused when public universities, specifically the major flagship institutions, which were deprived of state support, started to have their own private fundraising. Another cause was the development of a new philosophy of organizational management that stressed the significance of local decision-making and the ineffectiveness of large organizational structures with top-down management.

According to Berdahl, the research function of universities has assumed a major role in the "information age." Universities were regarded by their states, as agents of economic development. Being so, universities that are entrepreneurial-based needed to be liberated from state and system controls. The state of American public universities, which compete for skills with the country's finest private universities, is an important factor in the strength of the nation's research endeavor.

In the English milieu, however, the university system is formed by linking constituent colleges. In University of
Oxford, for instance, the academe is composed of school units and academic departments which are organized into four divisions. Based on the Introduction and History of University of Oxford, all the colleges are autonomous institutions as part of the university system. Every college administers its own membership and its own internal structure and activities. As a city university, the University of Oxford does not have a main campus; instead, all the buildings and facilities are distributed throughout the city center.

While establishing university links is common in England, merging of universities is familiar in Japan. The University of Tokyo and Osaka University, for instance, were formed by merging schools and faculties [7].

A university system is created based on definitive guidelines which includes the formation of a governing board tasked to devise policies common to all units of the system. Based on the CHED memorandum, a university system has a system administration that coordinates and integrates system-wide functions and activities. This is headed by a Chief Executive Officer whose primary duty is to implement policies that are approved by the governing board. This is consulted then with the heads of the colleges of the system. In the case of De La Salle University System, which was later renamed as De La Salle Philippines, was established under the presidency of Br. Andrew Gonzalez FSC in 1987 as a response to the rapid expansion of Lasallian schools nationwide [8]. As new presidents and chancellors were appointed, a network of campuses was established spreading the Lasallian Mission of bridging faith and scholarship in the service of society.

\subsection{Conceptual Framework}

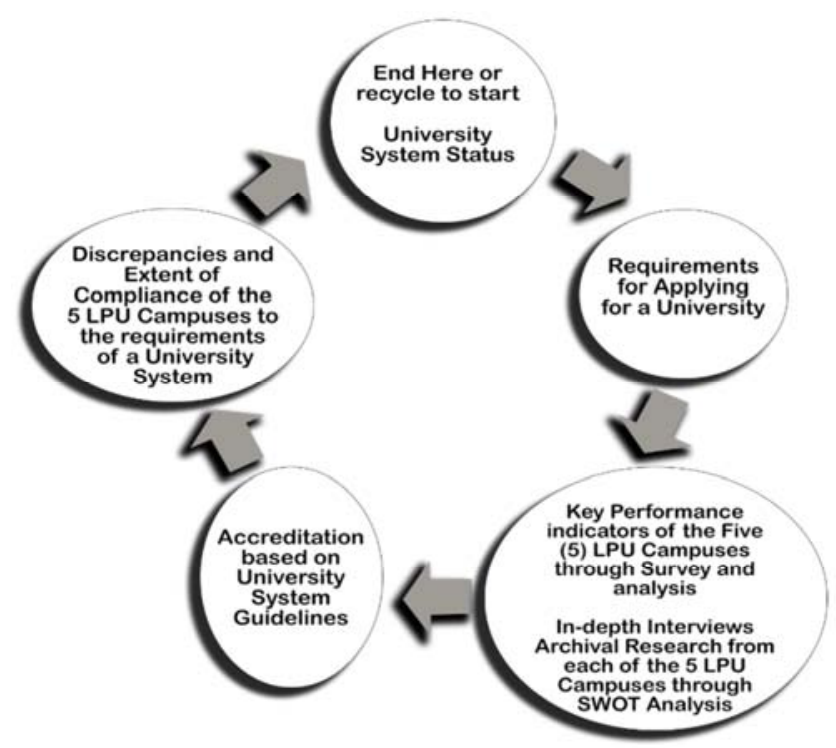

Figure 1. 5-Year Continuing Program to Meet the Requirements of a University System.

\subsection{Research Paradigm}

Based on the Provus' Discrepancy Model for Curriculum 
Evaluation Method, particular discrepancies can be determined and resolved between a pre-determined set of standards and what actually the current status of a particular area being studied. As such, the pre-determined set of standards is the requirements in applying for a university system and the present condition of the five (5) LPU campuses. The discrepancies and the extent to which the campuses have complied are subjected to improvement and accreditation as embodied the 5-year Continuing Program to meet the requirements.

Accordingly, six (6) stages need to be undergone in the process of evaluation and development, such as: developing a list of standards which specify the requirements, determining the information required to compare actual implementation with the defined standards, designing methods to obtain the required information, identifying the discrepancies between the standards and the actual status, determine reasons for the discrepancies, and eliminate discrepancies by making changes to the area being studied.

The discrepancy model does not prescribe, ideally, a specific technique for gathering and analyzing information. In this dissertation, however, survey questionnaire analysis of Key Performance Indicators as well as Strength-Weakness-Opportunities-Threats (SWOT) analysis are employed as technique which is discussed further in the Research Design section.

This paradigm approach only lists the stages required to plan the evaluation and development in meeting the requirements for obtaining a university system grant. This approach, being both qualitative and quantitative methods aims to determine the extent to which the campuses have complied with requirements and to eliminate, if not, reduce the discrepancies detected between what is prescribed in the requirements and current position of the campuses.

\section{Methodology}

\subsection{Research Design}

To seek answers to the set questions, this study used the Methodological Triangulation Approach that refers to the use of more than one method for gathering data. This means that a combined use of quantitative methodology and qualitative methodology are utilized to provide a more complete set of findings than could be arrived at through the administration of one of the methods alone. Triangulation offers the prospect of enhanced confidence on this study when it comes to its output since using of a single method may make the research suffer from limitations associated with a certain method or from the specific application of it.

This method can also be referred to as a multi-method research in which a quantitative and a qualitative research methods are combined to provide a more complete set of findings than could be arrived at through the administration of one of the methods alone. However, it can be argued that there are good reasons for reserving the term for those certain occasions in which researchers seek to check the validity of their findings by cross-checking them with another method.

In addition, this is specifically anchored on a discrepancy evaluation model based on what was developed by Malcolm Provus in 1966. This model shows a comparison of information of an actual occurrence or performance to a desired standard [9].

\subsection{Sources of Data}

In the quantitative area, a self-administered survey questionnaire was utilized. The questionnaire contained items that solicited the key performance indicators of the university being studied. A questionnaire is a form containing a set of questions, especially one addressed to a statistically significant number of subjects as a way of gathering information for a survey. In this study, a combination of dichotomous, where the respondent has two options and nominal-polytomous, where the respondent has more than two unordered options were also used [10].

A semi-structured interview guide was also employed in administration and retrieval of data for this study. Interviews were also conducted with a fairly open framework which allowed for focused, conversational, two-way communication. They were used both to give and receive information.

The data exhumed from the lenses of the informants provided a sufficient scenario being scrutinized, in a fashion that explains in account the perception of the individuals involved.

The research tools used by the researcher largely depends on the sincerity, thoughtfulness and objectivity of the respondents. Furthermore, the methodology used employed in this research is guarded against perceived biases.

\subsection{Documentary Analysis}

Major sources of documents include public records, the media, private newspapers, biography, official gazettes, minutes of meetings, strategies, policies, action plans by public bodies or organizations, reports and blueprints and visual documents including art works.

\subsection{Data Analysis}

Three types of information from the data gathering were extracted namely, nominal, interval and textual. Nominal and interval were gathered from the survey, while textual data were obtained from the interview. Four statistical tests were used to come with a sound and thorough processing of the raw data. These are as follows:

\subsubsection{Frequency}

This tool facilitates the tallying and counting of frequencies falling under each category. In this study, frequency was used to measure the respondents answer to specific set of questions.

\subsubsection{Percentage}

This was used to determine the trends of the subject of the study's statuses as well as the significant difference on the 
respondents' assessment. Specifically, this was used to compare the frequency of responses according to the number of sections.

\subsubsection{Likert Scale}

The Likert items took the following format:

$\begin{array}{ll}\text { SCALE RANGE } & \text { VERBAL INTERPRETATION } \\ 4.50 \text { to } 5.00 & \text { Very Evident } \\ 3.50 \text { to } 4.49 & \text { Evident } \\ 2.50 \text { to } 3.49 & \text { Relatively Evident } \\ 1.50 \text { to } 2.49 & \text { Doubtful } \\ 1.00 \text { to } 1.49 & \text { Not Evident at All / } \\ \text { Totally Not Observed } & \end{array}$

\section{Summary of Findings, Conclusions and Recommendations}

\subsection{Requirements in Applying for a University System}

To focus on the development of mass higher education without forgoing its delivery of quality education, a policy has been enacted by the Medium Term Higher Education Development Investment Plan of the Commission of Higher Education. This policy is for outstanding higher education institutions to transform themselves into University Systems.

Its first guideline stipulates that there must be a Governing Board. This body should have complete control and authority in organization and governance of the System. The same board should be responsible to create policies which are common to all the system's constituent unites. Moreover, the board should attain the institutions' purposes and objectives as prescribed in their own policies.

There must also be a System Administration which $\mathrm{s}$ should direct and incorporate system-wide functions and activities which should be headed by the University System's Chief Executive Officer as appointed by the governing board. The responsibilities of the Chief Executive should include the Governing Board itself, the implementation of policies as approved by the same board, and the administration of the system's operation. The rest of the officers of the system administration are accountable to the Chief Executive directly or coursed through channels. Some of the most significant tasks of the Chief Executive is consulting with the heads on the constituent units or colleges of the System regarding academic policies, recommending academic plans of constituent units or colleges, and presenting a budget for the whole University System.

To be a part of a University System, constituent units or colleges must have Level II accreditation of at least fifty-percent $(50 \%)$ of its offered Bachelor Degree programs. Likewise, there should be more than fifty-percent $(50 \%)$ of its tertiary student population enrolled in the programs being presented. In cases when a certain University System plans to enter another unit or college into its organization, an approval from CHED and compliance to the requirements pursuant to the memo must be obtained. Having its own Chief Executive
Officer and administration, the constituent unit should also hold certain functions: academic, administrative, and service. It is the governing board, however, that prescribes the extent of autonomy of each constituent unit and shall circumscribe its organizational structure.

The presence of an Academic Senate is likewise necessary.

This should comprise representatives from the regular faculty of each constituent unit in the University System. All academic policies for recommendation to the Board should be approved by the Academic Senate. Upon approval, these policies would then be applied to all constituent units. Such policies must include from the admission to the graduation of students, courses of study, and discipline. The scope of the role of the Academic Senate should be clearly defined by the Governing Board.

Similar to the Academic Senate, the University Council should be responsible in recommending to the governing board some academic policies which would be related only to a specific constituent unit but aligned with the policies of the entire University System. Parallel to the Academic Senate, the recommendations of the University Council should also be subjected to the Governing Board for approval before their implementation.

While financial planning and spending should be undertaken independently by each constituent unit, budget sharing among and between constituent units in the University System is recommended by the Governing Board when certain need arises.

Although each constituent unit has its own roster of faculty and staff, the Governing Board should devise policies for sharing and mobility of faculty members between and among units so that there would be maximum utilization of resources whether physical, human, or financial. This prospect of Faculty and Staff complementation must still be dependent on the requisites needed by a definite constituent unit or college.

Bachelor Degree Programs offered by the constituent units should complement each other. This must take into consideration the physical and human resources of each constituent unit as well as the needs and development concerns of the areas where the certain units are situated. On the other hand, CHED could grant a permit or authority to a specific private HEI to offer programs which do not necessarily apply to the whole University System where it belongs to.

To have effective utilization of resources and achieve greater goals, the University System should devise means to coordinate and integrate these services to all constituent units This should be done despite the thrust in research and extension that each constituent unit might have in response to its resources and need of its service area.

The Governing Board should formulate policies for accepting and recognizing course units earned by a student in one campus to another satellite campus within the same University System.

Conforming to the standards set by CHED, the facilities and equipment of each constituent unit should be existent and 
in use for instruction and laboratory purposes. Analogous to these, the Physical Plant of each constituent unit should also be existent and in use for the college/s within the campus.

Each constituent unit should have been granted, awarded, or entitled a designation, namely, deregulated status, autonomy, or center of excellence. Such designation should only apply to a specific university or college to which the entitlement is given and should not necessarily apply to the

Table 1 Requirements in Applying for a University System Title in Pursuant to CHED Guidelines.

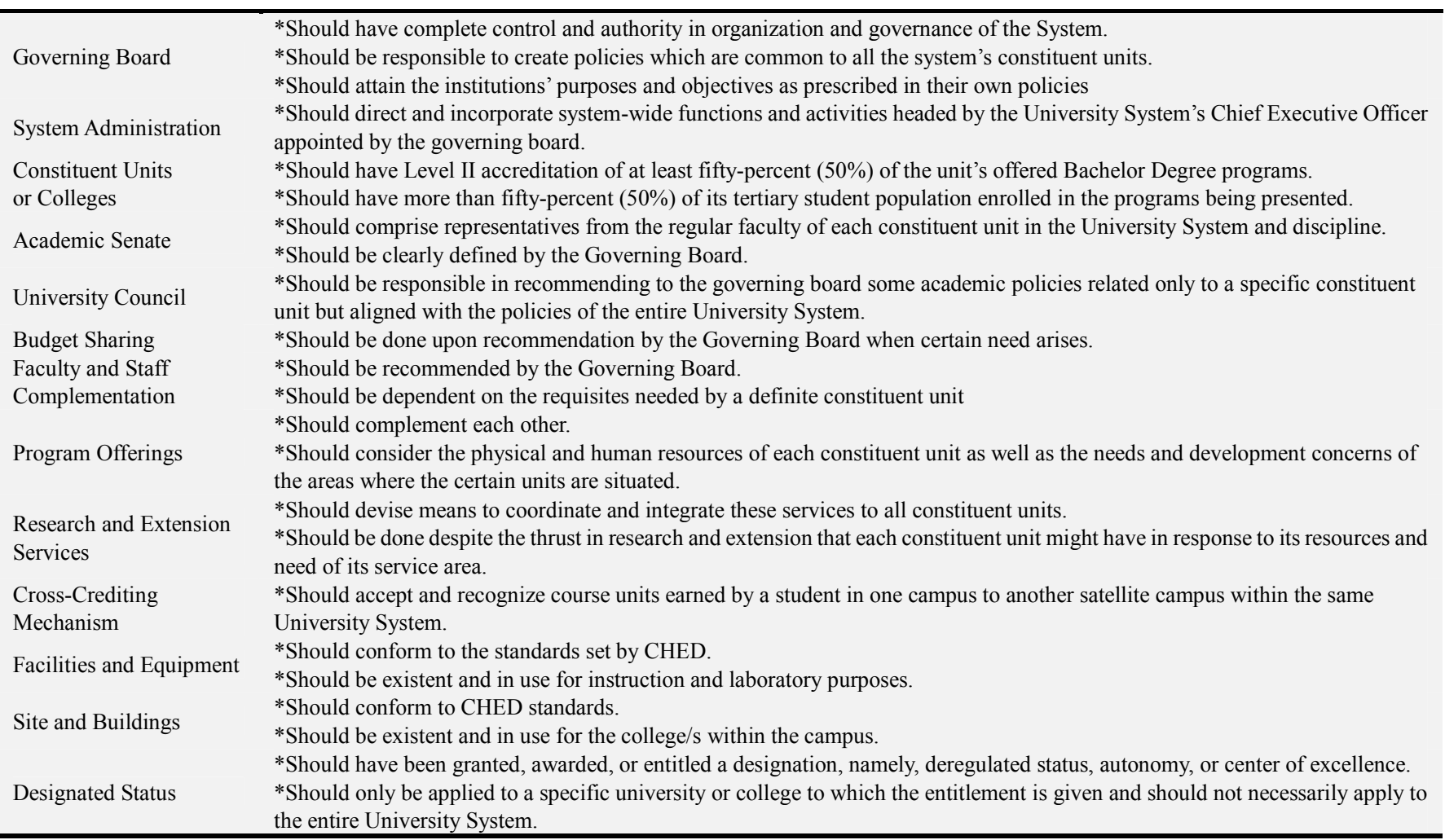

\subsection{Stages and Process of Transformation from University/College into a University System}

Based on synthesized interviews from different personnel-such University Presidents, Vice Presidents for Academic Affairs, Planning Officers, Deans, Directors, Heads, Coordinators, Faculty Representatives and Student Leaders from universities and colleges that belong to university systems - the following are general stages and processes that a university or college undergoes before transforming into a University System.

\subsubsection{Stage of Assessment and Identifying Potentialities}

This stage is where significant existing conditions, campus data or information are to be known and identified in order to make vital decisions for transformation. Most considerable to this stage is conducting a Strength-Weakness-Opportunity-Threat (SWOT) Analysis in order to ascertain potential growth of the unit.

\subsubsection{Stage of Strategic Planning}

This stage is where priorities and home institutional interests are set to strengthen its operation and resources as entire University System where the constituent unit belongs to unless specified in the grant. If the constituent unit has already been awarded or designated any status before its application to the University System, such status should not be significantly absorbed to the University System where the unit becomes a part nor to other units of the same University System. 


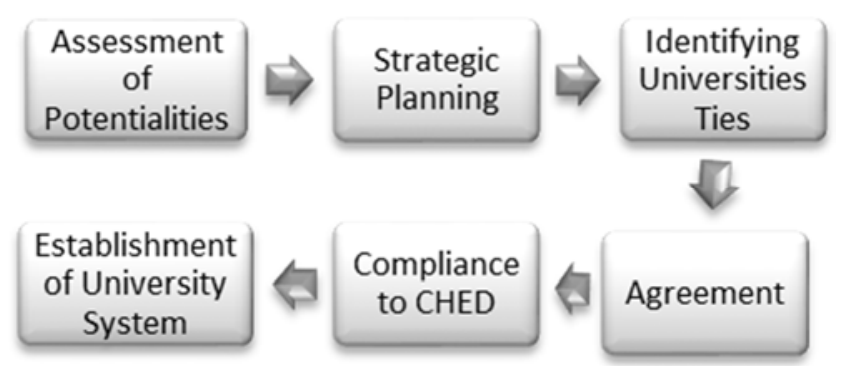

Figure 2. Stages of Transforming a University/College into a University System.

\subsection{Summary of Findings}

To determine the benefits that have been accorded to establish University Systems, 3 recognized university organizations have been analyzed and studied namely, St. Paul University System, University of Rizal System, and University of Perpetual Help Systems. This then confirms the extent of their compliance to the standards preset by apropos to those findings, 5 LPU campuses namely: LPU-Manila, LPU-Makati, LPU-Batangas, LPU-Laguna, and LPU-Cavite have also been subjected to the same study. This ascertains LPU's features as well as shows the gaps between and among the existing university systems and the 5 LPU campuses themselves. To obtain reliable data and information, it was important to develop viable approaches and method for this study. Once those were accomplished, this study was able to advance and create possibilities in using its findings for either preparing a continuing development plan to transform LPU institutions to a university system or publishing a primer for the transformation of excellent Higher Education Institutions to a university system. There were two kinds of survey instrument that were developed and used in gathering data in this study. The first instrument was the questionnaire which was administered to administrative personnel of different universities and colleges belonging to a University System as well as to each administration of LPU campuses. These questionnaires deal with the various benefits, factors and extent of compliance to the requirements of a University System set by the Commission. The other instrument was the personal interviews conducted with the same administrative personnel and executives in order to seek opinions or impressions germane to the study.

\subsection{St. Paul University System (SPUS)}

Operated by the Sisters of St. Paul of Chartres, SPUS has eight 8 satellite campuses in the Philippines governed by a Board of Chancellors. Based on CHED standards, SPUS marked the following benefits and factors as very evident in their system: Governing Body, System Administration, Constituent Units, Budget Sharing, Faculty and Staff Complementation, Program Offering, Research and Extension Services, Facilities and Equipment, and Site and Buildings. Its entitlement of full autonomy is also very evident which indicates that the universities can freely design and offer new curricular programs without much interference from the Commission. On the other hand, the existence of the Academic Senate, University Council, and Cross Crediting Policy is moderately evident. Overall, the benefits and factors accorded to SPUS is very evident. In terms of the extent of compliance to the requirements for a university system SPU campuses rated themselves as compliant to a high extent in the following requirements: Governing Board, System Administration, University Council, Budget Sharing, Faculty and Staff Complementation, Program Offering, Research and Extension Services, Facilities and Equipment, Site and Buildings, and Status. Meanwhile, the campuses being studied rated themselves as compliant to a moderate extent only in the areas of Constituent Units, Academic Senate, Cross Crediting or Transfer. SPUS, as a whole, has complied with a high extent to the requirements for a University System as embodied in CHED Memorandum Order.

\subsection{University of Rizal System (URS)}

URS maintains its satellite campuses in 10 Rizal provinces in the Philippines. On the benefits and factors accorded to University of Rizal System, the satellite campuses rated their Academic Senate as well as their Facilities and Equipment as moderately evident. Their System Administration, Constituent Units, Budget Sharing, Faculty and Staff Complementation, Program Offering, Research and Extension Services, Cross Crediting Transfer are observed as very evident. The areas pertaining to their Governing Board and University Council both share a verbal description of fully evident. Collectively, the benefits and factors accorded to URS are very evident. The extent of compliance of URS to the requirements for a University System as prescribed by the Commission in terms of its Governing Board, System Administration, Constituent Units, University Council, Budget Sharing, Faculty and Staff Complementation, Program Offering, Research and Extension Services, Site and Buildings, and Status are all to a high extent. Only the requirements of Academic Senate, Cross Crediting Transfer, and Facilities and Equipment are seen to be compliant to a moderate extent. On the whole, URS is compliant to a high extent to the conditions set by the Commission for a University System.

\subsection{University of Perpetual Help System (UPHS)}

Classified as a Catholic-oriented, co-educational, private University System in the Philippines, UPHS has 8 satellite campuses. The campuses rated its system as to be very evident in the benefits and factors accorded to it in terms of its Governing Board, System Administration, Constituent Units, University Council, Budget Sharing, Program Offering, Research and Extension Services, and Cross Crediting Transfer. But the area of Academic Senate, Faculty and Staff Complementation, Site and Buildings, and Status, received an observation of moderately evident. As whole, the benefits and factors accorded to UPHS is very evident. The extent of compliance of UPHS to the requirements for a University System pursuant to the guidelines of CHED has been marked 
compliant to a high extent in terms of Governing Board, System Administration, Constituent Units, University Council, Budget Sharing, Program Offering, Research and Extension Services, Site and Buildings, and Status. Its Academic Senate, Faculty and Staff Complementation, Cross Crediting Transfer, and Facilities and Equipment, are all rated compliant to a moderate extent only. In its total average, the UPHS is compliant to a high extent to the requirements for a University System.

\subsection{Lyceum of the Philippines University}

The 5 campuses of LPU marked themselves as compliant to a very high extent in the areas of Governing Board and Constituent Units, whereas the areas of Cross Crediting Transfer, Facilities and Equipment, and Site and Buildings were all indicated as compliant to a moderate extent. The rest of the areas met the requirements to a high extent. Those areas are: System Administration, Academic Senate, University Council, Budget Sharing, Faculty \& Staff Complementation, Program Offering, and Research and Extension Services. Taken as a whole, the campuses of LPU are able to conform to a high extent to the requirements for applying for a University System pursuant to the guidelines of the Commission.

\subsection{Gaps Between Lyceum of the Philippine University and the University Systems Studied}

LPU campuses perceived themselves as compliant to a very high extent in their Governing Board, Constituent Units, and Academic Senate. SPUS campuses, however, relatively marked themselves lower in those areas mentioned. The areas in which SPUS has higher rate than LPU are observed in Facilities and Equipment as well as Site and Buildings. This means that LPU still needs to improve those particular factors in comparison with SPUS. Between URS and LPU, the only marked difference is that campuses of LPU has higher perception of themselves to be compliant to a higher extent the requirements in applying for a University System compared with the level of compliance of URS. This is shown in the areas of Governing Board, Constituent Units, and Academic Senate. The only factor where URS rated themselves higher than LPU is Site and Building. This is probably because most URS campuses are situated in larger provincial areas compared with LPU campuses which are all situated in limited urban areas. Certain differences are also noted between UPHS and LPU. In most factors - such as Governing Board, Constituent Units, Academic Senate, Faculty and Staff Complementation, and Status, - UPHS is comparatively lower in their numbers than those in LPU. The only area where LPU campuses rated themselves lower is the Site and Buildings. This cam probably indicate that LPU does need to upgrade or renovate its physical plants in order to be at par with other established University Systems.

\subsection{Conclusions}

The reasonable particulars which reveal the various factors and requirements for applying for a university system pursuant to CHED Memorandum Order No. 08 s. 2003 were obtained from both the Commission memo and the interviews with administrative personnel in the different University Systems studied. These details were determined in response to research specific problem 1. The linking of constituent units certainly has to meet the requisites mandated by CHED. The existence of the Governing Board, System Administration, Academic Senate and University Council is a must. These serve as the cerebral components that direct the system's operations. Consolidated actions such as Budget Sharing, Faculty and Staff Complementation, Research and Extension Services, Cross Crediting measures are all indicative of the link between and among the units besides having correlative Course Offerings with at least Level II accreditation of fifty-percent (50\%) of them. Definitely, the Sites and Buildings of the constituent units along with their facilities and equipment are also considerable factors that are based on predetermined standards set by CHED for this purpose. Based on the relatively extent of data and information extracted from the administered survey questionnaires, the three university systems used as samplings for this study are compliant to a high extent to the requirements for a University System set by CHED. Moreover, the benefits accorded to them as such are also highly evident. Those data, therefore, resolve research specific problem 2. It can be inferred that they strictly follow and observe the CHED guidelines as preservation of their reputation and continuance of the benefits appropriated to them. The answer to research specific problem 3 is determined as the same questionnaires were conducted to the five (5) LPU campuses. Since their extent compliance on the requirement for applying for a University System is generally highly evident, it can be considered that these campuses are prepared to connect themselves and form a University System. Between and among the established university systems and the different campuses of LPU, that need to be addressed, certain gaps were also identified that satisfied research specific question 4 . Although the snags are minimal, this can be construed that LPU management has still areas to develop and improve for an ideal construction of Lyceum of the Philippines University System to realize. Finally, in response to research specific problems 5 and 6 , byproducts are devised. This includes the merging of LPU's strategic plans or continuing development plans to the factors and requisites in transforming into a University System. Another is the design of a primer that can be utilized by other higher education institutions for their transformation into a system. Given that the respondents were all academic officials and managers of different systems and college campuses, this study concludes that valuing and continuously upgrading higher education by transformation into a University System are indeed an unswerving drive towards attaining the goals that CHED promulgated.

\subsection{Recommendations}

Given the various requirements prescribed by the 
Commission, executives and academic administrators of LPU should include the factors and areas in linking and transforming the different campuses into University System. They should consolidate their strategic plan and coordinate policies in order to adapt to constant changes emerging from the society and the industries. By referring to this study, Higher Education Administrators should attempt to reorganize and rethink their approaches in order for them to operate as a structured system. As a system, they could easily facilitate operations that strengthen their potentialities and reduce their limitations. Students in higher education institutions should be more aware of their administrative school environment that directs them to be more observant of rules and regulations. They should always ascertain their track towards the mission-vision of the university where they are enrolled As part of a larger mechanism of a system, Higher Education Faculty Members should be more conscious of their vital role in their support for the university's mission and vision. Their learning objectives and student outputs should all be aligned in observance of the higher goals of their university. Researcher who will embark to similar studies as in this paper should use the information presented here as guideposts to recheck any changes or modification that may transpire in the course of time regarding university transformations.

\section{References}

[1] Primer on the Quality Assurance and Institutional Sustainability Assessment of HEIs, 2012.

[2] CHED Memorandum Order No. 08 s. of 2003.

[3] J. E. Scott, J. E., "Liberal Virtues" Oxford, England, Clarenden Press. 2001, p. 85.

[4] B. Gumport, "Contemporary Politics" and Education. London: Routledge, 2000 pp. 154-155.

[5] S. Bastedo, S. (2001). Policies and Change in Education. New York: New York. 2001, p. 108.

[6] N. Berdahl, N., "Thoughts on the History of University Systems in the US", CSHE, 2014, 122-125.

[7] Osaka University, "History of the Osaka University", Osaka Press, 2008, p. 9.

[8] De La Salle University, "DLSU General Information", DLSU Press, 2011, p. 14.

[9] N. Denzin, N., 2006, "Sociological Methods: A Sourcebook". Aldine Transaction, 5th edition, 2006, p.24.

[10] [10] W. H. Foddy, "Constructing questions for interviews and questionnaires: Theory and Practice in Social Research" (New ed.). Cambridge, UK: Cambridge University Press, pp. 227-230. 